Vantage: Journal of Thematic Analysis

ISSN: 2582-7391

A Multidisciplinary Publication of Centre for Research,

Maitreyi College, University of Delhi

October 2021, Volume 2, Issue 2

Invited Article

\title{
On the Significance of Plant Intelligence for Sound Cultivation
}

\author{
Savyasaachi* $^{*}$ \\ Department of Sociology, Jamia Millia Islamia, Delhi, India \\ ${ }^{*}$ Correspondence: savyasaachi@gmail.com
}

The contemporary agrarian crisis has three significant aspects. First, mainstream agrarian knowledge systems are created by manipulating plant living materials, depriving them of their resilience and immunity. Second, it increases the distance between the consumers and the producers of agricultural goods. Third, it gives low priority to the large population of marginal cultivators, who have to depend on government programmes and capital-rich farmers, especially when they run into crisis on account of crop failure and indebtedness.

I would like to argue that to overcome this crisis will require a shift to a radically different system of knowledge and its concomitant practices that understand the significance of plant intelligence. These practices will be averse to manipulating plant living materials, will give priority to marginal cultivators, and contribute to reducing the distance between the consumer and the producer. These attributes make a cultivation system sound.

Marginal farmers need to be given priority because they are the backbone of the agrarian system: they are a large workforce and several of them are sensitive to plant intelligence on account of a working day-to-day relationship with plants on cultivated land, and in landscapes.

\section{The Agrarian Crisis and Marginal Cultivators}

Mainstream modes of addressing the contemporary agrarian crisis use modern and traditional knowledge to enhance food crop production. The former uses pesticides, 
genetically modified seeds, and mega hydro-electric dam-based canal irrigation. The latter uses organic manures, indigenous seeds, lift-irrigation, etc. The intention of using traditional knowledge is to undo the damage caused by modern agricultural knowledge, such as loss of crop and seed biodiversity, loss of nutritional substance, loss of crop resilience, loss of ground water etc.

These two knowledge systems are the basis of agricultural practices as well as of their respective social structures that can be sustained by rich and some middle class farmers who have capital reserves and large farms.

\section{Limits of mainstream Knowledge}

The contemporary agrarian crisis is a consequence of the alienation of landscapes of non-human nature from the cultivation of food crops. An aspect of this alienation is the indifference to the autonomy of landscapes of a non-human nature (both living and nonliving) and disrespect for the way members of such landscapes - plants, birds, animals, trees, mountains, rivers, insects, etc. - communicate with and relate to each other and to human beings, contributing to shaping an inclusive collective social life.

It can be argued that this alienation over time created conditions for the innovation, use and dependence on pesticides, genetically manipulated seeds, and dependence on international market price fluctuations. This alienation has also exposed non-human landscapes to rising pollution and its cumulative resultant phenomenon - climate change. This severely damaged communication networks between members of human and non-human nature.

The motivation to do away with such dependence with organic farming, biodynamic farming and natural farming etc., have caught the imagination of several entrepreneurs. This is a welcome development. However, it is not sufficient to heal the damage to nonhuman nature caused by exposure to pollutants and their cumulative phenomenon, climate change.

Working with forest dwellers, I witnessed a tradition of communication between plants and human beings. There is a resonance of this in the discussions on plant intelligence. Here, non-anthropocentric intelligence is coming to light. This could become the basis 
for sound cultivation of food crops, contributing to building and enriching communication between humans and non-human nature, thereby overcoming their alienation for an inclusive collective social life.

\section{Plant Intelligence and Landscape Cultivation}

Koitors are forest dwellers who describe their habitat as Shringar Bhum. Geographically, they are located in North Bastar, Chhattisgarh. They are marginal cultivators who practice landscape cultivation.

They understand plant intelligence as the basis of systems of communication and interconnections between human beings and all aspects of living landscapes. They recognise that a living landscape is the habitat of communication between communities, plants, animals, waterways, hills, mountains, and stones. On the one hand they understand that this social life of living landscapes is autonomous, and interdependent with human beings existing alongside. On the other hand, they also understand that human beings with a different autonomous system of communication have an equally interdependent relation with plants. They acknowledge that this interdependence is relative to the presence of each in the neighbourhood of the other. That is to say, their co-presence assures their respective autonomy.

Their landscape cultivation practice ensures a healthy and happy landscape which is described by them as Shringar Bhum. This practice has the following four aspects:

First, it is based on the knowledge of the life cycle of water, plants and animals in order to harvest them in tune with their rhythms. For instance, not to eat fruits before they are mature.

Second, it requires the skill of making small clearings marked for this purpose alone, selected on the basis of vegetation type and topsoil quality. For instance, non-fruit bearing trees predominate and vegetation on the ground is low.

Third, at the foundation of this practice are sacred groves, from where nothing can be taken or removed, not even a dry leaf fallen on the ground. Such sites are distinguished by sacred trees that are propitiated. 
Fourth, to be cognizant that the intention of such practice is to enrich the topsoil, do nothing that will destroy it, and do everything to enrich it.

The underlying principle is: "that which is not the product of human labor cannot be possessed and has to therefore be looked after, taken care of." This principle informs the relationship between human beings and the landscape, its mode of use and a sense of responsibility towards it.

Koitors ensure that in their yearly cultivation cycle the relation between the small clearing and the landscape is mediated by fallow cultivation. That is to say, fallow cultivation orients small clearing cultivation. Fallow cultivation refers to no interference, with the intention to show respect to plural time of life cycles that shape a living landscape. During this time the clearing is not cultivated. This is the time when human and non-human nature come together as a community, in communication nurtured by each other's quiet presence. Fallow is inclusive of all living beings, human and non-human. It ensures the welfare of all.

Koitors indicate that crops cultivated in small clearings, plants in the landscape, water ways, hills, mountains and stones communicate with each other, and have a social life. They share their sorrows, their joys, their life experiences, in the process enhancing each other's potential. On account of this social life, a living landscape makes everyone feel happy. This shows in the uprightness, the texture, the luminous colours and the abundant diversity of life forms.

Some Koitor elders described to me an important aspect of this communication system - a robust system of exchange between the clearing and its surrounding landscape. This, they argued, follows from the principle underlying landscape cultivation, namely, that which is not a product of one's labor cannot be owned and has to be cared for. The boundaries between them are defined by reciprocal welfare. For instance, the cultivated crop in the clearing is not the exclusive property of human beings and equally, the edible plants are not exclusive to the landscape. For instance, living beings in the landscape can eat cultivated plants and the human beings gather food from landscapes. 
If this principle is respected in the cultivation practices, then both (human beings and non-human living beings in the landscape) will take only so much that it will not deprive the others. According to the Koitors, the practice of fencing (guarding) cultivated clearings from living beings inhabiting the landscape (such as animals), begins when human beings begin to deprive them of their share.

Conceptually, fallow time in landscape cultivation fosters conjoint behaviour, discussed by John Dewey in his article on "Social as a Category" (Dewey, 1928). Conjoint behaviour enhances the potential of togetherness.

Denial of the opposition between the social and the natural is, however, an important element of the meaning of "social" (p165)....Social phenomena are not of themselves, of course, equivalent to social as a category (p168). ...When we return to the social, we find that communication as the existential occurrence involved in all distinctly communal life, and we find that communication effects meaning and understanding as conditions of unity or agreement in conjoint behaviour ( $p 172$ )...The view of those is superficial who fail to see that in the social the physical is taken up into a wider and more complex and delicate system of interactions so that take on new properties by release of potentialities previously confined because of the absence of interaction ( $\mathrm{p} 169)$.

A testimony to the efficacy of this principle is that between the village settlement and the forest there are no fences, land is contiguous. During the day Koitors visit the forest and at night the forest beings come to visit the settlement.

This demonstrates that intersubjectivity with non-living beings ensures conjoint behaviour. Respect for plant intelligence presupposes reverence for life, which is absent in current agricultural practices. It is equally possible that the experience of intersubjectivity with plants can induce reverence for life.

\section{Fallow Time, Marginal Cultivators and Plant Intelligence}

Not all marginal cultivators have their small productive clearings nested in forested landscapes. A large majority are far from the forest, with their unproductive clearings in the midst of barren landscapes. They have to work with knowledge systems (both modern and traditional) that do not harness the potential of fallow time. Fallow time is 
seen as a liability on the monetary cycles of capital reproduction. To be polite, there is no respect whatsoever for living forms, who are manipulated slaves. These are of mere instrumental value for achieving economic and political objectives. Here plants are deprived of their social life by destroying their conjoint behaviour. Human and nonhuman beings are alienated from each other.

Koitors have worked with marginal cultivators to restore the landscape and generate productive clearing. In their experience, the process begins with including fallow time as an integral component of marginal farmers. The making of a sacred grove inaugurates fallow time. Here, species native to the geography of the place are given a sanctuary to mature at their own rhythm, free from any pressure from the markets and time-bound performance. During this time, plant intelligence has the opportunity to work. Plants, in this sanctuary, open up communication channels with the rest of the landscape - above the earth and under it - and other living beings begin to come to this sanctuary. It prepares the ground for cross pollination and inaugurates a food chain.

This is the beginning of the restoration process.

\section{Understanding Plant Intelligence}

In the observer-centred view, thinking and intelligence are used interchangeably, as aspects of the mind located in the brain.

Intelligence of beings with a brain is reflected in thinking, which may or may not translate into communication. Intelligence of beings without brains, such as plants, is reflected in the way they communicate, undeterred by the 'absence of thinking'.

The distinction comes from the difference in their modes of memory.

Heidegger in his first lecture on "What is Called Thinking (Heidegger, 1954, p. 3-4)" says:

Memory is the gathering of thought. Thought of what? Thought of what holds us, in that we give it thought precisely because It remains what must be thought about. Thought has the gift of thinking back, a gift given because we incline towards it. Only when we are so inclined towards what in itself is to be thought about, only then are we capable of thinking. 
Here memory, inclusive of recollection and remembering, is the gift of thinking "back" in order to hold on to it. We also know that this gift of thinking guided by concepts, words and images is grounded in labour teleology (as discussed by Lukacs (1978)).

Indigenous voices across the world have indicated that this mainstream knowledge system is based on and promotes anthropocentric intelligence. What this means is that it is observer-centric in so far as it privileges the observer over the observed. It has been pointed out that the gaze of the mainstream knowledge system has 'fixed' not only people but the entire realm of non-human as 'observed' under the microscope or under surveillance. This gaze denies subjectivity to the observed.

It is suggested in the example of landscape cultivation that indigenous people put forward a different point of view: all non-human nature - animals and plants along with other aspects of the landscape - constitute a living system and therefore have intelligence. To know of this, Koitors point out that the realm of non-human nature is observing the observer. This is as if, when walking in a particular landscape, say the forest, a person is aware that the trees, the birds, the insects, the hills ... are saying to each other, "we know who this person is". They remember.

Memory plays a very significant role here. But here memory is not the gift of thinking back.

In this regard, Rupert Sheldrake (1988) tells us about animals:

In 1980's neuroscientists discovered that when animals watched other animals doing something, for example a monkey peeling a banana, changes in the motor part of their brains mirrored those in the brain of animals they were watching. These responses were described in terms of 'mirror neurons'. But this term is misleading if it suggests a special kind of nerve. This is better thought of as a kind of a resonance. In fact, Vittorio Gallese, one of the discoverers of the mirror neuron refers to the imitation of movements or actions by another individual as 'resonance behaviour'

Here, memory that mirrors resonance is an aspect of 'mind' (that is not a gift of thinking). This could be described as an aspect of the 'Inclusive of Mind'. 
Stefano Mancuso (2017) argues:

It isn't too difficult to imagine that intelligence is not the product of one single organ but that it is inherent in life, whether there is brain or not...

With regard to plants, Stefano Mancuso, in a discussion on "Memories without a brain" argues:

"All plants are capable of learning from experience and therefore have memorization mechanisms. If you submit a plant, for example an olive tree, to a stress such as drought or salinity, it will respond by implementing the necessary modifications to its anatomy and metabolism to ensure its survival. Nothing unusual in that, right? If, after a certain amount of time, we submit the same plant to the exact stimulus, perhaps with an even stronger intensity, we notice something that is surprising only on the surface: this time, the plant responds more effectively to the stress than it did the first time, It has learnt its lesson".

Memory here is not determined by the 'gift of looking back' and is not an expression of teleology of labour, its agency and practice. It is not the ability to not forget, or the capability to memorise facts and figures. This memory, with or without a brain, records resonances of experiences that give rise to morphic structures. It retains the imprint of the event mirrored.

Plants are intelligent: they communicate with each other and memorise the resonances of human beings. They do not require a brain.

In this communication, the observer is observed by animals and plants. With the awareness of being observed by animals and plants, the observer begins observing 'itsself,' and this makes it possible to 'see,' the difference and relationship between one's (observers) own self and the entire realm of non-human nature wherein the act of observation is happening.

In this recursive reciprocal communicative relationship-'the observer is the observed'clears the ground to explore the intelligence of plants. The intersubjectivity generated from the reciprocity of the observer and the observed makes it possible to see that 
'thinking' is only one aspect of intelligence. Thinking communicates conceptual intelligence only as an aspect of the 'inclusive mind ${ }^{1}$, which is located not only in the physical brain material, but in other physical materials of trees and plants. Its resonances continue to exist independently after the physical matter decomposes and dissolves, in the course of its life cycle. This recursive reciprocal communication triggers a semiosis.

Eduardo Kohn (2013) argues that we can understand how forests think by observing semiosis:

Semiosis is the name for this living sign process through which one thought gives rise to another, which in turn gives rise to another, which in turn gives rise to another, and so on, into the potential future (Kohn, 2013, p. 33).

This understanding of semiosis is observer-centric. By describing it as a chain reaction of thoughts, it excludes the intersubjectivity of the observed (plants and animals). It does not account for several ethnographic passages, in the book, that suggest that the amazon people are aware of being observed by animals. This oversight is because the definition of semiosis focuses on a chain reaction of thoughts which are expressions of thinking associated with a particular kind of memory described earlier as 'thinking back'.

Animal and plant memorization, as we have noted, are mirror resonances (and are not memorizations thinking back).

The observer-observed intersubjectivity between human and non-human beings defines the non-anthropocentric semiosis of the inclusive mind. Plant semiosis can be observed in the subtle behavioural changes acknowledging co-presence.

Richard Grant (2018) in his article "Do trees talk to each other?", shares his conversation with German Forester Peter Wohlleben, a tree whisperer.

Wohlleben takes me to two massive beech trees growing next to each other. He points up at their skeletal winter crowns, which appear careful not to encroach

\footnotetext{
${ }^{1}$ It is inclusive of the teleological mind
} 
into each other's space. "These two are old friends," he says. "They are very considerate in sharing the sunlight, and their root systems are closely connected. In cases like this, when one dies, the other usually dies soon afterward, because they are dependent on each other.

Co-presence is seen in conjoint behaviour (discussed above). Whispering is a mode of communicating presence, it is free of signs, symbols, signals all of which constitute non-verbal visual concepts. Whispers are soft sounds to be uttered and received in most intimate relations. It is quiet communication between quiet beings.

Eduardo Kohn misses out on the whispers. In a discussion on "knowing without knowing," he wonders:

How could Ameriga, Delia, and Luisa presume to guess at what their dogs were thinking?...Granted, that Ameriga, Luisa and, Delia will never know with certainty what their dogs were thinking...but they could make some good guesses (Kohn, 2013, p.86).

Eduardo does take this wonderment to Ameriga, Delia, and Luisa! The reader is left wondering what these three ladies would have said!!!

We take Eduardo's question to Peter Wohlleben: 'How did he know the intimacy between the two massive beech trees growing next to each other?'

I cannot speak for Peter Wohlleben. However, I can venture to share my understanding. Peter Wohlleben heard the whispers between the two big birch trees.

Good guesses are necessary when there is lack of attunement.

Peter Wohlleben and the trees are perhaps attuned to each other!! His entire work in "Secret Networks of Nature (Wohlleben, 2017)" is testimony to his attunement.

\section{Social Structure for Sound Cultivation}

A social structure for sound cultivation is not in agreement with the current agricultural practices based on modern and traditional knowledge, because both evolved to kill plant subjectivity and are scornful of any attempt to explore human-plant intersubjectivity. In 
both systems of knowledge the observer's gaze fixes a frame to manipulate their being, as it were.

Rich and middle level farmers will remain far away from social structures of whispering, as long as they are wedded to these two systems. For this reason they will not get the benefit of plant wisdom necessary for sound cultivation.

Some marginal cultivators are plant whisperers. They are likely to be open to work with foresters, ecologists, botanists and anthropologists who are sensitive to plant intelligence and know the value of man-plant intersubjectivity.

\section{For Discussion}

There are three significant aspects of the knowledge on which sound cultivation is based:

1. The gift of thinking located in the brain is only one instance of intelligence. It is observer-centric and anthropocentric.

2. Communication with the semiosis of 'feeling co-presence' amongst beings that do not think with brains, reflects intelligence of an 'Inclusive Mind'.

3. This semiosis is integral to the human-plant intersubjectivity.

In order to grasp this with an open mind and engage with it, observer-centric ideas of subjectivity and intelligence reflected in thinking will have to be bracketed.

\section{CONFLICT OF INTEREST}

There are no competing interests.

\section{REFERENCES}

Dewey J (1928). Social as a Category. The Monist, 38 (2), 161-177. https://doi.org/10.5840/monist192838218

Heidegger, M. (1954). What is Called Thinking? Translated by Gray, J. G. (pp. 3-4). New York: Harper \& Row.

Lukacs, G. (1978). The Ontology of Social Being-3. Labour. Translated by David Fernback. London: Merlin Press. 
Sheldrake, R. (1988). The Presence of the Past-Morphic Resonance and the Habits of Nature. (pp.269-270). New York: Vintage.

Mancuso, S. (2017). The Revolutionary genius of Plants-A New Understanding of Plant Intelligence and Behaviour. (pp. 5). New York: Atria Books

Kohn, E. (2013). How Forests Think-Toward an Anthropology beyond the Human. Berkeley: University of California Press.

Grant, R. (March, 2018). "Do Trees talk to each other?" Smithsonian Magazine, https://www.smithsonianmag.com/science-nature/the-whispering-trees$\underline{180968084 /}$

Wohlleben, P. (2017). The Secret Network of Nature-The delicate Balance of All living Things. Translated from German by Jane Bilinghurst, J. London: The Bodley Head, An imprint of Vintage.

How to cite this article: Savyasaachi (2021). On the significance of Plant Intelligence for Sound Cultivation. Vantage: Journal of Thematic Analysis, 2(2):

DOI: https://doi.org/10.52253/vjta.2021.v02i02.02

(C) The Author(s) 2021.

This work is licensed under a Creative Commons Attribution 4.0 International License which permits its use, distribution and reproduction in any medium, provided the original work is cited. 